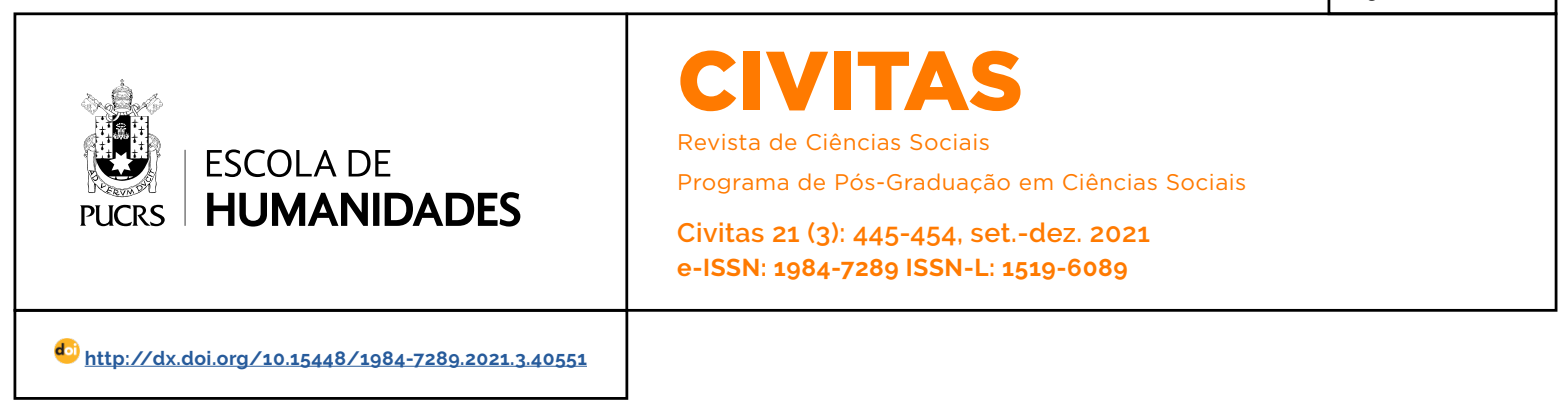

DOSSIÊ: INTERSECCIONALIDADES, DIREITOS E POLITITICAS

\title{
Sobre usos e possibilidades da interseccionalidade
}

On uses and possibilities of intersectionality

\author{
Sobre usos y posibilidades de la interseccionalidad
}

\section{Bruna Cristina Jaquetto Pereira $^{1}$}

orcid.org/0000-0003-3213-8672 brunacjpereira@gmail.com

Recebido em: 31 mar. 2021. Aprovado em: 18 ago. 2021. Publicado em: 8 nov. 2021.

\section{(c) (1)}

Artigo está licenciado sob forma de uma licença Creative Commons Atribuição 4.0 Internacional.
Resumo: Neste artigo destaco o potencial de um uso particular do conceito da interseccionalidade. Inicialmente, recupero de modo breve o histórico do conceito, discuto estudos que analisam como ele vem sendo utilizado no âmbito das ciências sociais a partir do final da década de 1980 e, em seguida, apresento um modelo próprio de análise, que enseja radicalizar o olhar interseccional e capturar camadas complexas das relações sociais. Busco, com isso, superar definitivamente a perspectiva da soma de opressões e as análises interseccionais que privilegiam ora um dos sistemas de subordinação, ora outro(s). A ideia apresentada junta-se a outras possibilidades de emprego da interseccionalidade como dispositivo heurístico

Palavras-chave: Interseccionalidade. Modelos de análise. Desigualdades.

Abstract: In this article, I highlight the potential of a particular application of the concept of intersectionality. Initially, I briefly retrieve the concept's history, discuss studies that analyze how it has been used in the social sciences since the late 1980s, and then present a peculiar analysis model, which allows radicalizing the intersectional look and capture complex layers of social relations. In doing so, I seek to definitively overcome the perspective of the sum of oppressions and the intersectional analyzes that privilege sometimes one of the subordination systems, sometimes other(s). The presented idea adds to other possibilities of using intersectionality as a heuristic device.

Keywords: Intersectionality. Analysis models. Inequality.

Resumen: En este artículo destaco el potencial de un uso particular del concepto de interseccionalidad. En primer lugar, recupero brevemente la historia del concepto, analizo estudios que consideran cómo se lo ha utilizado en las ciencias sociales desde finales de la década de 1980 y luego presento un modelo de análisis propio, que permite radicalizar la mirada interseccional y capturar capas complejas de las relaciones sociales. Con esto, busco superar definitivamente la perspectiva de la suma de opresiones y los análisis interseccionales que privilegian ahora uno de los sistemas de subordinación, ahora otro(s). La idea presentada se suma a otras posibilidades de utilizar la interseccionalidad como dispositivo heurístico.

Palabras clave: Interseccionalidad. Modelos de análisis. Desigualdades.

\section{Introdução}

Uma das grandes questões debatidas pelas ciências sociais é o tema das diferenças e das desigualdades: como são construidas, experimentadas e reproduzidas, qual a natureza da relação entre os diversos grupos sociais, como apreendê-las. Embora a relação entre diferentes tipos de desigualdade já fosse considerada por certas(os) autoras(os), 
foi a partir dos anos 1970 que se observou uma onda de questionamentos à produção marxista, ao feminismo de segunda onda (Biroli e Miguel 2015) e ao pensamento sobre raça (Collins e Bilge 2016), que consideravam, respectivamente, o capitalismo, o patriarcado ou o racismo como elemento explicativo único ou primordial de produção de diferença, desigualdade, exploração, dominação e opressão nas sociedades modernas. As criticas defendiam que uma análise mais precisa demandava que se contemplasse sistematicamente a combinação entre dois ou mais "eixos de opressão" (Collins 2002, 248) ou "sistemas de subordinação" (Crenshaw 2002. 176) - termos que serão utilizados a seguir de modo intercambiável.

Foi a produção intelectual de ativistas e de intelectuais não brancas (no Brasil, de mulheres negras; na África do Sul, durante as lutas anticoloniais e contra o apartheid; nos Estados Unidos, de ativistas afro-americanas, chicanas, latinas, indigenas e asiáticas) entre 1960 e 1980 que passou a defender de modo assertivo que gênero, raça e classe não operam em separado. Suas análises consideravam como tais fatores estavam amalgamados em seu funcionamento, fundando assim uma perspectiva interseccional - se não ainda propriamente o conceito de interseccionalidade. Como mulheres, não brancas e trabalhadoras, e ainda como intelectuais envolvidas em discussões de tópicos então em pauta - o colonialismo, o racismo, o sexismo, o militarismo e a exploração capitalista -, elas propuseram que o patriarcado, o racismo e o capitalismo, como sistemas de opressão, dominação e exploração, existem e operam de forma articulada, influenciando-se mutuamente (Collins e Bilge 2016). Ainda que com menor consistência, fatores como sexualidade, geração, habilidade/ deficiência, nacionalidade, idioma e religião também passaram a ser considerados como sistemas de subordinação imbricados e relevantes à análise social, a depender do contexto.

Nos Estados Unidos, formulações teóricas sobre a combinação entre os eixos de opressão foram impulsionadas pelo Combahee River Col- lective e por figuras como Audre Lorde, Angela Davis e bell hooks, e, na Inglaterra, por autoras como Hazel Carby e Nira Yuval-Davis. Chegando à África do Sul, tal produção reforçou as críticas já existentes ao feminismo hegemônico (branco e ocidental) e contribuiu para a construção de modelos emancipatórios alternativos (Nkealah 2016). Na França, Colette Guillaumin e Danièle Kergoat foram as principais autoras a promover a discussão - apesar do foco primordial em gênero e classe. No Brasil, Lélia Gonzalez (Rios e Lima 2020) foi pioneira na promoção desse debate no ambiente acadêmico. Alguns dos termos inicialmente utilizados para descrever as articulações entre diferentes sistemas de subordinação foram "discriminação composta", "cargas múltiplas" e "tripla discriminação" (Crenshaw 2002, 177), sugerindo uma soma mecânica dos tipos de dominação (Dennis 2008). Nos anos 1980 , consolidou-se a visão de que as desigualdades nas sociedades contemporâneas não podem ser entendidas levando-se em conta apenas gênero, raça ou classe social (Biroli e Miguel 2015): os três fatores deveriam ser entendidos e analisados em sua atuação conjunta.

Foram então elaboradas ou consolidadas abordagens que superam a noção de soma, dedicadas a capturar a complexidade da relação entre os diversos sistemas de subordinação. Embora conceitos como os de consubstancialidade, de Danièle Kergoat (2010), e a metáfora do nó, de Heleieth Saffioti (2004), sejam eventualmente empregados em análises sociológicas, de longe, o conceito que ganhou maior visibilidade e que mais impactou a produção acadêmica e o ativismo desde sua formulação foi o de interseccionalidade.

No presente artigo, dedico-me a apresentar brevemente tal conceito/paradigma (Collins e Bilge 2016), para então revisar dois estudos sobre como ele tem sido empregado no âmbito das ciências sociais. Em seguida, descrevo como mobilizei o conceito para analisar minha pesquisa empírica sobre vivências afetivo-sexuais de mulheres negras. Reproduzo o modelo que empreguei na investigação e argumento que tal uso da interseccionalidade pode dar visibili- 
dade a aspectos até então pouco considerados da interface entre distintos eixos de produção de diferenças, desigualdades e hierarquias nas sociedades modernas. A ideia sugerida soma-se a possibilidades já existentes de uso da interseccionalidade como dispositivo heurístico para a investigação comprometida com o enfrentamento a situações de injustiça social.

\section{Interseccionalidade: surgimento e definição}

O termo "interseccionalidade" foi cunhado em 1989 pela jurista estadunidense Kimberlé Crenshaw, como crítica do feminismo negro à tendência a se abordar "raça e gênero como categorias mutuamente exclusivas de experiência e análise" (Crenshaw 1989, 139, tradução minha). Herdeira das intelectuais negras que a precederam e da teoria racial crítica, ao formular o conceito, a autora nomeou compromissos teóricos e políticos que já existiam, e que, ainda que de modo difuso, integravam, sobretudo, o pensamento e a práxis de mulheres não brancas (Nash 2008; Collins e Bilge 2016; Viveros Vigoya 2016).

Crenshaw (1989) alegou que as análises que empregam gênero ou raça como categorias unitárias de subordinação resultam no apagamento teórico de mulheres negras, sobretudo no que se refere à conceitualização, identificação e enfrentamento à discriminação racial e "por sexo". As análises tradicionais sobre a discriminação racial privilegiariam homens e pessoas negras das classes altas, e as apreciações da discriminação "por sexo" teriam por foco mulheres brancas e de classes privilegiadas. Apenas adicionar "mulheres negras" a análises derivadas de categorias únicas não seria suficiente para refletir de maneira adequada as discriminações em tela.

Crenshaw (1991, 2002) concebe a realidade social como constituida por diversos sistemas de discriminação que interagem entre si de maneiras distintas, conformando múltiplas dimensões da experiência. Desse modo, as experiências sociais de sujeitos e de coletividades marginalizados (e, a meu ver, também as dos que dispõem de privilégios relativos) seriam sempre multidimen- sionais. Para que tal interação entre sistemas de discriminação e seus efeitos seja adequadamente capturada, a autora defende que o exame das discriminações (por exemplo, de gênero e de raça) deve partir do setor em maior desvantagem dentro de grupos discriminados porque sujeito à discriminação combinada. Além disso, apenas o enfoque interseccional sobre as experiências dos setores marginalizados dentro de grupos discriminados (no caso, das mulheres negras) garantiria que análises e políticas de combate à discriminação alcançassem a todas(os) (Crenshaw 1989).

Nota-se que o conceito da interseccionalidade teve origem em preocupações quanto à inclusão de grupos invisibilizados e excluídos. A questão da diferença, embora relevante, aparece como secundária e só ganha sentido quando relacionada ao combate à discriminação, à subordinação e à marginalização, ou seja, à promoção da justiça social (Alexander-Floyd 2012; Collins e Bilge 2016). Como as tradições feminista e da teoria racial crítica de que é herdeira, a interseccionalidade congrega em sua origem tanto desígnios teóricos quanto políticos (Nash 2008).

Crenshaw apresentou elaborações adicionais sobre a interseccionalidade, agregando, inclusive, atenção à portabilidade do conceito para outros contextos. Ela afirma que gênero, raça e classe, bem como outros eixos de opressão (etnia, nacionalidade, religião, sexualidade, geração, habilidade/deficiência ou outros, a depender do contexto), configuram "sistemas de subordinação/discriminação" que não são totalmente distintos ou mutuamente excludentes. Ao contrário, eles sobrepõem-se e entrecruzam-se, e, de maneira dinâmica, criam intersecções complexas e geram desigualdades básicas e posições relativas entre mulheres, grupos étnicos ou raciais, classes sociais etc. Assim, o conceito ilustra o fato de que o impacto de uma fonte de subordinação pode variar, dependendo de sua combinação com outras fontes de subordinação ou privilégio relativo (Dennis 2008).

No entanto, os desafios com os quais um grupo social discriminado por dois ou mais sistemas depara-se podem permanecer obscurecidos quando 
a análise social adota exclusivamente uma abordagem de gênero ou racial. A metáfora do cruzamento entre ruas (em inglês, intersection) é empregada pela autora para dar visibilidade a grupos cuja posição social configura-se a partir do encontro entre dois ou mais eixos de poder (Crenshaw 2002).

Crenshaw (2002) afirma que os eixos de discriminação e de subordinação são historicamente constituídos e não operam igualmente em todos os tempos e lugares. A autora também alega que aqueles que se sobressaem e combinam-se em cada contexto variam. Por isso, defende que a interseccionalidade seja utilizada para a construção de modelos provisórios, que produzam análises contextuais e "de baixo para cima", ou seja, que partam da realidade de grupos marginalizados e vulneráveis em uma dada sociedade para a apreensão de categorias de discriminação relevantes, evitando-se assim a imposição de categorias analíticas a uma dada situação.

Ao longo de sua carreira, Crenshaw vem ressaltando que nunca pretendeu que o conceito se desdobrasse em uma teoria geral da opressão e que o seu compromisso está no emprego prático da interseccionalidade, voltado para a análise e o enfrentamento a desigualdades concretas. Contudo, ele se tornou "o tropo feminista mais difundido para falar tanto de identidades quanto de desigualdades múltiplas e interdependentes" (Viveros Vigoya 2016, 5. tradução minha), e adquiriu vida própria.

Uma vez formulado, o termo foi incorporado rapidamente pelo feminismo negro estadunidense, de onde se disseminou. Atualmente, a "interseccionalidade" é utilizada para referir-se não apenas a desigualdades e opressões, mas também à construção de identidades coletivas, laços de solidariedade entre grupos e aos ativismos políticos mobilizados em oposição a processos de subordinação (Biroli e Miguel 2015). Empregada também na produção bibliográfica europeia e latino-americana (Viveros Vigoya 2015), a interseccionalidade hoje faz-se presente em diferentes disciplinas (filosofia, ciências sociais, economia, direito), perspectivas teóricas (fenomenologia, estruturalismo, pós-estruturalismo, liberalismo, psicanálise, desconstrucionismo), preocupações políticas (feminismo, antirracismo, multiculturalismo, estudos queer e estudos sobre deficiência) e níveis de análise (micro e macro) (Davis 2008; Carbim e Edenheim 2013; Viveros Vigoya 2015) - não sem que se tenham diluidos seus intentos políticos originais (Viveros Vigoya 2015: Collins 2019). Em seus múltiplos usos, já foi definida como "sensibilidade analítica" (Cho, Crenshaw e McCall 2013, 795), "paradigma, conceito, abordagem, dispositivo heurístico e teoria" (Collins e Bilge 2016, 31), transformando-se em um termo "guarda-chuva" (Collins 2019, 692) ou "ponto nodal" (Cho, Crenshaw e McCall 2013, 788).

A popularidade do termo e sua incorporação substantiva e dinâmica pela produção acadêmica feminista justifica-se por algumas de suas características centrais: o conceito interpela a visão binária sobre gênero e raça; dá visibilidade e incorpora sujeitos excluidos pelas análises feministas e antirracistas tradicionais (Nash 2008); captura a complexidade da vida social (Collins e Bilge 2016); e reúne ideias de diferentes lugares, tempos e perspectivas (Collins 2019). Além disso, sua "abertura" e "ambiguidade" (Davis 2008, 67) garantem a flexibilidade que a consagrou como estratégia para se lidar com o problema das identidades e desigualdades múltiplas, colocado às perspectivas críticas e politicas identitárias as mais distintas. É nesse sentido que Collins enxerga a interseccionalidade como uma "ferramenta heurística" (Collins e Bilge 2016, 4) - ou seja, como uma construção artificial ou conceito geral que auxilia na investigação de fenômenos sociais - aplicável a situações e problemas os mais variados.

As críticas à interseccionalidade são diversas, e referem-se, por exemplo, à imagem geométrica que o termo evoca (Kergoat 2010); à dificuldade de se definir quais são as assimetrias a se levar em consideração em uma determinada análise (Biroli e Miguel 2015); à ambiguidade e ausência de uma metodologia bem definida (Nash 2008); à inexistência de uma teoria sobre poder ou sujeito (Carbin e Edenheim 2013).

Apesar dos questionamentos, o conceito já foi assimilado como parte essencial do pensamento feminista. Com efeito, a interseccionalidade 
transformou o modo como se discute gênero e possibilitou a incorporação de sujeitos até então invisibilizados ao feminismo. Por sua importância, o termo chegou a ser apontado como a principal contribuição do campo dos Women's Studies (McCall 2005).

\section{Usos da interseccionalidade}

Sumi Cho, Kimberlé Crenshaw e Leslie McCall (2013) enxergam três niveis de engajamento com o conceito da interseccionalidade: em abordagens interseccionais ou em investigações de dinâmicas interseccionais, em estudos sobre contextos e temas especificos; em debates sobre o escopo da interseccionalidade enquanto paradigma teórico e metodológico, no esforço para compreender-se como a interseccionalidade tem sido adotada; e em intervenções políticas que adotam uma lente interseccional.

Atendo-me à segunda finalidade, no Brasil, ainda que a produção acadêmica sobre gênero incorpore cada vez mais a perspectiva interseccional, são escassos os estudos sobre como isso vem sendo feito em termos teóricos e metodológicos. Ana Claudia Pereira (2019) identifica duas tendências na bibliografia nacional, tendo em vista o entendimento sobre a natureza dos sistemas de subordinação, da relação entre eles e sua concepção sobre o racismo. Na primeira delas, a interseccionalidade é mobilizada com a mera função "operacional" de capturar aspectos especificos da identidade nas pesquisas empiricas. Tais estudos, em geral, abraçam teorias pós-estruturais do sujeito, às quais se conjugam a absorção acritica de "construtos ideológicos que afirmam a existência de uma democracia racial no Brasil" (Pereira 2019, 79). Já gênero figura como o eixo de opressão ou marcador social da diferença principal. A segunda vertente considera gênero, raça e classe como categorias que, entrelaçadas, forjam hierarquias que organizam a vida social. Tais estudos compreendem "o racismo como um sistema de subordinação e exploração a que estão submetidas todas as pessoas negras" (Pereira 2019, 79). Além disso, não se considera que haja prioridade de um eixo sobre os demais.
Por outro lado, revisões bibliográficas e análises sobre o uso da interseccionalidade são abundantes na língua inglesa, e englobam tanto a produção estadunidense e canadense como a europeia, embora exista uma lacuna de estudos sobre sua aplicação no contexto sul-africano. Neste artigo, atenho-me a apresentar duas propostas de sistematização do emprego da interseccionalidade no âmbito das ciências sociais, tendo em vista aspectos teóricos e metodológicos.

Em seu artigo "The complexity of intersectionality", Leslie McCall (2005) preocupa-se em definir como se deve operacionalizar a pesquisa sobre interseccionalidade no âmbito das ciências sociais - ou seja, com as implicações metodológicas do conceito. A autora identifica três abordagens principais, com base na compreensão e uso das "categorias analiticas". A interseccionalidade, afirma, agrega maior complexidade à análise da vida social. Mas o leque de possibilidades analiticas que ela abre é muito amplo. Como não é possivel agregar todas as categorias sociais a todas as dimensões da análise, para manejar tal complexidade, cada uma das abordagens elencadas emprega uma estratégia metodológica distinta.

A primeira abordagem identificada por McCall (2005, 1776) é a da "complexidade anticategórica". A prioridade é a desconstrução das categorias analíticas pelo questionamento ao próprio processo de construção e de definição de fronteiras. A vida social é considerada irredutivelmente complexa, de maneira que o uso de categorias fixas seria inviável ou indesejável. A autora define-a como a abordagem mais adequada a um projeto político individualista (em oposição a uma perspectiva coletiva e estrutural) e, por isso, seria pouco referida por mulheres não brancas, a quem interessaria manter a visibilidade de categorias que produzem desigualdades.

A segunda abordagem nomeada por McCall (2005, 1775) é a da "complexidade intracategórica". Como a primeira, ela caracteriza-se por questionar o processo de construção e de definição de fronteiras; no entanto, ao contrário da anterior, reconhece, ao mesmo tempo, as relações estáveis e duráveis representadas pelas categorias 
sociais. Procura fugir das generalizações homogeneizantes ao focar no processo de produção, vivência e reprodução das categorias e mesmo na resistência a elas. Sua estratégia para manejar a complexidade da realidade social é manter o foco do estudo em um único grupo social subordinado, para assim tratar de diversas dimensões e de seu funcionamento dentro de uma única categoria, empregando métodos qualitativos de investigação.

A terceira abordagem apontada por McCall (2005, 1784) é a da "complexidade intercategórica", que se define pelo uso provisório e estratégico das categorias analíticas. O foco recai sobre o reconhecimento das relações estáveis e duráveis estabelecidas pelas categorias em análise. Seu objetivo é documentar e examinar as relações de desigualdade entre grupos sociais já constituidos (ainda que provisórios e em constante transformação), de modo que as relações estruturais são privilegiadas na análise. Sua estratégia metodológica principal é o uso de métodos quantitativos para a produção de análises comparativas (McCall 2005).

A tipologia sugerida por McCall (2005) revela duas preocupações que atravessam a utilização da interseccionalidade na pesquisa e que as/os cientistas sociais frequentemente devem, de algum modo, equacionar em seus trabalhos: por um lado, o manejo do caráter histórico e contextual dos sistemas de subordinação e o caráter social das construções identitárias e categorizações; por outro, a necessidade de se considerar as assimetrias de poder e opressões, sem as quais o termo se dissociaria de seu sentido político. Não se trata de questões novas: a relação entre antiessencialismo e políticas identitárias, bem como o caráter contextual da combinação entre sistemas de subordinação, estiveram presentes nos escritos iniciais de Crenshaw (1991, 2002). $\mathrm{O}$ artigo de McCall (2005), no entanto, situa o problema no nível metodológico.

Por sua vez, Hae Choo e Myra Ferree (2010), no artigo "Practicing Intersectionality in Sociological Research", buscaram sistematizar trabalhos sociológicos que empregam a perspectiva interseccional para estabelecer parâmetros relativos a seu uso teórico e metodológico no estudo de desigualdades. Seu argumento principal é que os estudos sobre desigualdades se tornariam mais efetivos se incorporassem perspectivas de grupos marginalizados e tratassem as desigualdades como multiplamente determinadas e interligadas, ao invés de eleger uma única instituição central de análise. Para tanto, propõem as autoras, as(os) sociólogas(os) disporiam de três tipos de ferramentas: a interpretação centrada na inclusão, o modelo centrado em processos e a análise sistêmica.

A interpretação centrada na inclusão parte do entendimento de que diferentes pontos de vista podem revelar aspectos distintos das configurações de poder (Choo e Ferree 2010), e está visivelmente alinhada à teoria do ponto de vista (ou standpoint theory) (Collins 2002). Ter voz, além de uma reivindicação política, é visto por Choo e Ferree (2010) como uma demanda apresentada à própria produção intelectual. Portanto, a ferramenta visa a dar espaço tanto para as experiências sociais quanto para as perspectivas de grupos multiplamente discriminados (Choo e Ferree 2010). O exemplo clássico é a inclusão de mulheres negras e suas perspectivas analíticas à pesquisa social.

O modelo centrado em processos (ou interseccionalidade como interação analítica) tem como foco não mais os grupos ou categorias, mas as dinâmicas interseccionais de combinação entre eixos de opressão. Ele refere-se à tradução da interseccionalidade ao âmbito da metodologia e busca superar a perspectiva aditiva. Para tanto, 0 modelo dedica-se a considerar como a interação de um eixo de opressão (por exemplo, gênero) com outros eixos (por exemplo, classe e raça) em um determinado contexto transforma-o, de modo a compreender como a interação entre diferentes "estruturas de dominação" gera variações. Neste modelo, é possivel propor que um dos eixos de poder é o principal gerador de desigualdades em um dado cenário. A análise comparativa e a atenção ao contexto são suas principais estratégias investigativas (Choo e Ferree 2010).

O modelo da interseccionalidade sistêmica também prioriza as dinâmicas interseccionais. Porém, ao invés de ater-se a contextos especifi- 
cos, as desigualdades são pensadas em múltiplos niveis (estrutural e interpessoal) e em relação às instituições. Segundo as autoras, quando se emprega tal estratégia, os eixos são vistos como continuamente em interação, o que desfavorece a noção de que um processo em particular constitua o principal fator gerador de desigualdades (Choo e Ferree 2010). A meu ver, trata-se de conceber as sociedades como multidimensionais, e de empregar a interseccionalidade para enxergá-la em sua complexidade. De acordo com esse modelo, por exemplo, o capitalismo e a política econômica são compreendidos não apenas como "saturados" pela classe social, mas como constituidos também pelas relações de gênero e raça (Choo e Ferree 2010).

Tomando as considerações de McCall (2005) e de Choo e Ferree (2010) em conjunto, as questões levantadas pelas autoras trazem à tona quatro preocupações com as quais a abordagem interseccional deve lidar: a visão antiessencialista (portanto, histórica e contextual) das categorias sociais; as assimetrias de poder e o problema das opressões; a preocupação com a inclusão de grupos marginalizados, bem como de suas prioridades e perspectivas/interpretações da realidade; e a noção de que as desigualdades são multiplamente determinadas e estão interligadas.

\section{Uma proposta de modelo analítico interseccional}

Em minha pesquisa sobre vivências afetivo-sexuais de mulheres negras (Pereira 2020), na qual priorizei a interseccionalidade de gênero e raça, formulei um modelo investigativo que primou por fugir de alguns lugares-comuns e armadilhas da análise interseccional. Ao apresentar e examinar contextos, dinâmicas e padrões de interação coletados durante a pesquisa empírica, pareceu-me pouco produtivo recorrer à estratégia de análise que busca identificar ora gênero, ora raça, ou que favorece um deles como sistema de subordinação principal e fundamento explicativo, o qual o outro transforma.
Por um lado, considero que tais visões mantêm o lugar das experiências sociais típicas de mulheres brancas de classes médias/altas como referência de gênero, e dos homens negros como o padrão quando se fala sobre raça. Por outro, estava interessada em compreender como gênero e raça, combinados ou a se interpelar, operam em situações concretas de interação social. Busquei, então, uma alternativa que aprofundasse o potencial da interseccionalidade como desestabilizador de binários (Nash 2008). Inspirada em Crenshaw (2002) e Oyèrónkẹ Oyěwùmi (1997), estive atenta à necessidade de evitar impor categorias "de cima para baixo" à análise dos contextos sociais.

Entre 2016 e 2018, realizei entrevistas com 14 mulheres negras ${ }^{2}$ (pretas e pardas) que viviam no Distrito Federal (DF). O perfil das entrevistadas abrange um espectro diverso quanto a idade (23 a 56 anos), estado civil (solteira, união estável, casada), classe social (baixa, média ou alta) e orientação sexual (homossexuais, bissexuais e heterossexuais). Secundariamente, realizei observações em espaços de sociabilidade do DF (festa Batekoo e espaços de samba) e no grupo de Facebook Afrodengo e, ainda, apliquei uma enquete junto a usuárias de aplicativos de paquera.

$\mathrm{Na}$ análise do material, identifiquei três elementos articuladores das dinâmicas observadas: estética, sexualidade e moralidade sexual. Notei então que cada um deles referia-se simultaneamente a gênero e raça. Por isso, pareceu-me frutífero considerar gênero e raça como "interseção" (Kerner 2012) ou como "eixos concêntricos" (Viveros Vigoya 2016), em alinhamento ao modelo de interseccionalidade sistêmica proposto por Choo e Ferree (2010) - ao invés de tomá-los como entidades separadas. Parti de uma definição de gênero e raça como sistemas de significado e regimes de representação e destaquei que, na sociedade ocidental moderna e no contexto específico do Brasil, sua história, conteúdo moral, lógicas de sentido, vocabulários, imaginários, não caminham em paralelo cruzando-se apenas eventualmente, mas são, 
antes, muitas vezes compartilhados, mutuamente referidos e mesmo indissociáveis. Por exemplo, como eixos articuladores de diferenças, desigualdades e hierarquias, tanto gênero quanto raça compartilham categorizações referidas aos binários "natureza e cultura", "ativo e passivo", e "superior" (ou "normal") e inferior" (Collins 2002). Dai a possibilidade de estabelecer-se referências mútuas, como notado por outras(os) autoras(es): a recorrente feminização das terras conquistadas; a representação dos homens não brancos como emasculados ou feminizados e das mulheres não brancas como masculinizadas; a comparação dos povos não brancos às mulheres - já que ambos estariam mais próximos da natureza, em estado "selvagem" (Stoler 1995; McClintock 2010).

Dessa forma, verifiquei que estética, sexualidade e moralidade sexual "costuravam" a articulação entre gênero e raça nas interações sociais analisadas. Com menção a outras(os) autoras(as) e nuanças históricas e contextuais, argumentei que a estética concerne tanto ao imperativo da beleza imposto às mulheres quanto à associação entre negritude e feiura no imaginário nacional. A sexualidade recupera as expectativas normativas de recato sexual às mulheres (às quais se contrapõe a noção de apetite sexual masculino acentuado ou incontrolável) e também a associação das(os) negras(os) à sexualidade exacerbada (uma vez que entendidas(os) como "selvagens" e em oposição à associação da branquitude à intelectualidade). Já a moralidade sexual diz respeito a "discursos e códigos morais" (Moore 2008) que versam sobre a (in)adequação das ligações: quem deve se relacionar com quem, como lem que tipo de relacionamento ou vínculo) e onde (em público ou no espaço privado, em segredo), bem como os significados da obediência às regras e consequências quando são transgredidas. Aqui, entram em jogo tanto a cisão entre ligações consideradas legitimas e ilegítimas tendo em vista a etiqueta racial brasileira quanto noções de respeitabilidade ou lassidão moral feminina.

Cada um dos três fatores, propus, é central para a construção da teia de significados e prescrições hegemônicos relacionados tanto a gênero quanto raça, e é, ainda, estruturante dos modos como a afetividade e a sexualidade são configuradas, compreendidas e experimentadas (Pereira 2020).

Com vistas a ilustrar as vantagens da estratégia proposta, destaco alguns dos resultados que alcancei a partir da estratégia analítica delineada. Em primeiro lugar, noto que o discurso de gênero, explícito, possibilitou a articulação do discurso racial de maneira implícita - o que é particularmente importante em um contexto no qual o racismo funciona, muitas vezes, de modo disfarçado (Gonzalez 1988). Por exemplo, Aurora, uma das entrevistadas, percebeu-se negra pela primeira vez quando, ainda criança, foi xingada de "puta" por um colega branco na escola. Ela apreendeu uma ofensa, em geral associada à sexualidade feminina, como simultaneamente referida ao modo como é racialmente classificada, ao menor status atribuido a seu grupo racial, aos significados sexuais atribuidos aos(às) negros(as) e à sexualidade desvirtuada como um indicador de status social inferior.

O segundo achado que destaco diz respeito às relações inter-raciais, sobretudo heterossexuais. Introduzindo nuances à narrativa de que esse tipo de união atesta a inexistência de barreiras raciais, verifiquei que as relações entre mulheres negras e homens brancos e (em menor medida, entre mulheres negras e mulheres brancas) estiveram condicionadas à demarcação da mulher negra como alguém diferente, tendo em vista seus supostos atributos (e atrativos) sexuais. Tal enquadramento resulta na demarcação do envolvimento inter-racial como uma transgressão do sujeito branco às fronteiras de seu grupo racial, sendo o contato para além de seu segmento racial de origem regulado por códigos da moralidade sexual - que prescrevem relações informais e baseadas no sexo, mas vetam casamentos -, os quais thes permitem preservar tais fronteiras. As transgressões a esses códigos resultam em sistemáticas intervenções e ataques ao casal, seja por parte da familia branca, de amigas(os) ou desconhecidas(os) brancas(os).

Um terceiro achado aponta que os traços físicos associados à negritude são, muitas vezes, vividos 
pelas mulheres negras com sofrimento, ou ao menos considerados como algo a ser administrado (vigiado e controlado). O cabelo foi o atributo racial sobre o qual as entrevistadas discorreram mais abertamente, e operou como uma metáfora para que falassem da negritude em geral: quando positivamente ressignificados, tais atributos não deixam de ser vistos como algo a ser controlado de perto. Por outro lado, a pesquisa indicou que o discurso dos ativismos negros tem fornecido às mulheres negras modelos estéticos que operam como alternativas ao imaginário hegemônico racista. As referências por ele oferecidas, se não são capazes de substituir completamente conteúdos simbólicos e prescrições comportamentais normativos - sistematicamente inscritas em sua subjetividade pelo processo de socialização e pelas contínuas interações -, apresentam-lhes alternativas mais vantajosas, destituidas do olhar inferiorizante projetado a partir do grupo racial de maior status (Pereira 2020).

Trata-se de resultados e análises complexos, que dificilmente teriam sido obtidos a partir de uma visão da interseccionalidade como "ora gênero, ora raça", ou então como "raça transformando gênero".

Além disso, o modelo analítico delineado congrega as quatro preocupações centrais de uma abordagem interseccional listadas na seção anterior. Ao priorizar na análise o desenvolvimento histórico e as características contextuais das categorias sociais em tela, ele afasta qualquer visão essencialista sobre as mesmas, ao mesmo tempo em que estimula a(o) pesquisadora(r) a averiguar as conexões entre elas. As desigualdades e as opressões tornam-se visiveis como multiplamente determinadas e interligadas. Simultaneamente, o modelo traz a possibilidade de levar-se em conta as vozes e as perspectivas das entrevistadas e demais participantes da pesquisa sem, com isso, incorporar acriticamente discursos nativos sobre gênero e raça (ou sobre outras categorias sociais analisadas), sobretudo quando naturalizam desigualdades e opressões. Desse modo, ele atende ao compromisso politico original da interseccionalidade. Ao mesmo tempo, tanto recuperar inicialmente a história e a configuração contextual dos sistemas de subordinação explorados (sua simbologia, linguagem e sentidos) como identificar fatores que os articulam concretamente na interação entre sujeitos e em seus discursos tornam mais visiveis as assimetrias de poder existentes, seu funcionamento e recriação no dia a dia.

\section{Considerações finais}

Como alternativa à estratégia de análise interseccional que busca identificar na pesquisa de campo o funcionamento ora de gênero, ora de raça (ou de outros eixos de opressão), ou que presume a prioridade de um deles em um dado fenômeno ou contexto social, proponho que a retomada histórica e a compreensão das características contextuais dos sistemas de opressão considerados orientem a()o pesquisadora( $r$ ) na identificação de fatores que funcionam como articuladores entre tais sistemas no âmbito do objeto investigado. Que elementos discursivos, simbólicos, imagéticos e morais estão presentes nas interações e discursos dos sujeitos e referem-se simultaneamente a gênero e raça (ou a outros eixos de opressão)? Como eles são mobilizados nas interações, e com quais efeitos para as relações sociais?

O modelo descrito, sugiro, enseja uma visão mais radical da interseccionalidade dos sistemas de subordinação, além de adequar-se a preocupações centrais para a abordagem interseccional nos dias de hoje. Ele favorece, ainda, a produção de análises interseccionais mais complexas, capazes de revelar camadas ainda pouco exploradas das relações sociais.

\section{Referências}

Alexander-Floyd, Nikol G. 2012. Disappearing acts: reclaiming intersectionality in social sciences in post-black feminist era. Feminist Formations 24 (1): 1-25. https://doi.org/10.1353/ff.2012.0003.

Biroli, Flávia e Luís Felipe Miguel. 2015. Gênero, raça, classe: opressões cruzadas e convergências na reprodução das desigualdades. Mediações 20 (2): 27-55. https://doi.org/10.5433/2176-6665.2015V20n2p27. 
Carbin, Maria e Sara Edenheim. 2013.The intersectional turn in feminist theory: a dream of a common language? European Journal of Women's Studies 20 (3): 233-248. https://doi.org/10.1016/j.wsif.2013.07.013.

Cho, Sumi, Kimberlé Crenshaw e Leslie McCall. 2013 Toward a field of intersectionality studies: theory, applications, and praxis. Signs 38 (4): 785-810. https://doi. org/10.1086/669608.

Choo, Hae Y. e Myra M. Ferree. 2010. Practicing intersectionality in sociological research: a critical analysis of inclusions, interactions, and institutions in the study of inequalities. Sociological Theory 28 (2): 129-149. https:// doi.org/10.2307/25746220.

Collins, Patricia H. 2019. Intersectionality as critical social theory. Durham: Duke University Press.

Collins, Patricia H. 2002. Black feminist thought: knowledge, consciousness and the politics of empowerment. 2. ed. Nova York: Routledge.

Collins, Patricia Hill e Sirma Bilge. 2016. Intersectionality. Cambridge: Polity Press.

Crenshaw, Kimberlé. 2002 Documento para o encontro de especialistas em aspectos da discriminação racial relativos ao gênero. Revista Estudos Feministas 10 (1): 171-188. https://doi.org/10.1590/ S0104-026X2002000100011.

Crenshaw, Kimberlé. 1991. Mapping the margins: intersectionality, identity politics, and violence against women of color. Stanford Law Review 43 (6): 12141-12199. https://doi.org/10.2307/1229039.

Crenshaw, Kimberlé. 1989. Demarginalizing the intersection of race and sex: a black feminist critique of antidiscrimination doctrine, feminist theory and antiracist politics. University of Chicago Legal Forum 1989 (1) 8: 139-167. http://chicagounbound.uchicago. edu/uclf/vol198g/iss1/8.

Davis, Kathy. 2008. Intersectionality as buzzword: a sociology of science perspective on what makes a feminist theory successful. Feminist Theory 9 (67): 67-85. https://doi.org/10.1177/1464700108086364.

Dennis, Ann. 2008. Intersectional analysis: a contribution of feminism to sociology. International Sociology 23 (5): 677-694.https://doi.org/10.1177/0268580908094468.

Gonzalez, Lélia. 1988. Por un feminismo afrolatinoamericano. Isis: an international review devoted to the history of science and its cultural influences 9: 133-141.

Kerner, Ina. 2012.Tudo é interseccional? Sobre a relação entre racismo e sexismo. Novos Estudos Cebrap 93: 45-58. https://doi.org/10.1590/S010133002012000200005 .

McCall, Leslie. 2005. The complexity of intersectionality. Signs 30 (3): 1771-1800. https://doi.org/10.1086/426800.

McClintock, Anne. 2010. Couro imperial: raça, gênero e sexualidade no embate colonial. Campinas: Unicamp.

Moore, Henrietta L. 2008. The subject of anthropology: gender, symbolism and psychoanalysis. Cambridge: Polity Press.
Nash, Jennifer C. 2008. Re-thinking intersectionality. Feminist Review 89 (1): 1-15. https://doi.org/10.1057/ fr.2008.4.

Nkealah, Naomi. 2016. (West) African feminisms and their challenges. Journal of Literary Studies 32 (2): 6174. https://doi.org/10.1080/02564718.2016.1198156.

Oyěwùmi, Oyèrónkẹ. 1997. The invention of women: making an african sense of western gender discourses. Minneapolis: University of Minnesota Press.

Pereira, Ana Claudia Jaquetto. 2019. Intelectuais negras brasileiras: horizontes politicos. Belo Horizonte: Letramento.

Pereira, Bruna C. J. 2020. Dengos e zangas das mulheres-moringa: vivências afetivo-sexuais de mulheres negras. Pittsburgh: Latin America Research Commons.

Rios, Flavia e Márcia Lima. 2020. Introdução. In Por um feminismo afro-latino-americano: ensaios, intervenções e diálogos, organizado por Flavia Rios e Márcia Lima, 9-21. Rio de Janeiro: Zahar.

Saffioti, Heleieth. 2004. Gênero, patriarcado, violência. São Paulo: Fundação Perseu Abramo.

Stoler, Ann Laura. 1995. Race and the education of desire. London: Duke University Press.

Viveros Vigoya, Mara. 2016. La interseccionalidad: una aproximación situada a la dominación. Debate Feminista 52: 1-17. https://doi.org/10.1016/j.df.2016.09.005.

\section{Bruna Cristina Jaquetto Pereira}

Doutora em Sociologia pela Universidade de Brasilia (UnB), em Brasilia, DF, Brasil; professora do Instituto de Relações Internacionais na mesma instituição.

Os textos deste artigo foram revisados pela Poá Comunicação e submetidos para validação da autora antes da publicação. 